\title{
Structure of the Suasselkä postglacial fault in northern Finland obtained by analysis of local events and ambient seismic noise
}

\author{
Nikita Afonin ${ }^{1}$, Elena Kozlovskaya ${ }^{2,3}$, Ilmo Kukkonen ${ }^{4}$, and DAFNE/FINLAND Working Group* \\ ${ }^{1}$ Federal Centre for Integrated Arctic Research RAS, Arkhangelsk, Russia \\ ${ }^{2}$ Oulu Mining School, POB-3000, 90014, University of Oulu, Finland \\ ${ }^{3}$ Geological Survey of Finland, P.O. Box 96, 02151, Espoo, Finland \\ ${ }^{4}$ Department of Physics, University of Helsinki, P.O. Box 64, 00014, Helsinki, Finland \\ *A full list of authors and their affiliations appears at the end of the paper. \\ Correspondence to: Nikita Afonin (afoninnikita@inbox.ru)
}

Received: 9 June 2016 - Discussion started: 12 July 2016

Revised: 10 January 2017 - Accepted: 13 March 2017 - Published: 18 April 2017

\begin{abstract}
Understanding the inner structure of seismogenic faults and their ability to reactivate is particularly important in investigating the continental intraplate seismicity regime. In our study we address this problem using analysis of local seismic events and ambient seismic noise recorded by the temporary DAFNE array in the northern Fennoscandian Shield. The main purpose of the DAFNE/FINLAND passive seismic array experiment was to characterize the presentday seismicity of the Suasselkä postglacial fault (SPGF), which was proposed as one potential target for the DAFNE (Drilling Active Faults in Northern Europe) project. The DAFNE/FINLAND array comprised an area of about 20 to $100 \mathrm{~km}$ and consisted of eight short-period and four broadband three-component autonomous seismic stations installed in the close vicinity of the fault area. The array recorded continuous seismic data during September 2011-May 2013. Recordings of the array have being analysed in order to identify and locate natural earthquakes from the fault area and to discriminate them from the blasts in the Kittilä gold mine. As a result, we found a number of natural seismic events originating from the fault area, which proves that the fault is still seismically active. In order to study the inner structure of the SPGF we use cross-correlation of ambient seismic noise recorded by the array. Analysis of azimuthal distribution of noise sources demonstrated that during the time interval under consideration the distribution of noise sources is close to the uniform one. The continuous data were processed in several steps including single-station data analysis, instrument response removal and time-domain stacking. The data were
\end{abstract}

used to estimate empirical Green's functions between pairs of stations in the frequency band of $0.1-1 \mathrm{~Hz}$ and to calculate corresponding surface wave dispersion curves. The Swave velocity models were obtained as a result of dispersion curve inversion. The results suggest that the area of the SPGF corresponds to a narrow region of low S-wave velocities surrounded by rocks with high $\mathrm{S}$-wave velocities. We interpret this low-velocity region as a non-healed mechanically weak fault damage zone (FDZ) formed due to the last major earthquake that occurred after the last glaciation.

\section{Introduction}

In studying of mechanisms of large earthquakes investigations of seismogenic fault structure and properties are of particular importance. One group of seismological studies concentrates on mapping the seismic source using recordings of seismic events. This includes mapping of the fault plane using distribution of hypocentres of earthquakes originating from the fault and also calculating orientation and dip of fault planes from seismograms of earthquakes (fault plane solutions, centroid moment tensor solutions). Another group of methods investigates the inner structure of fault zones using structural geology, palaeoseismology, seismic reflection and refraction experiments and geodetic measurements. The studies of the second group show that the inner structure of seismogenic faults is complex (Davis and Reynolds, 1996) and the main slip planes are surrounded by so-called fault 


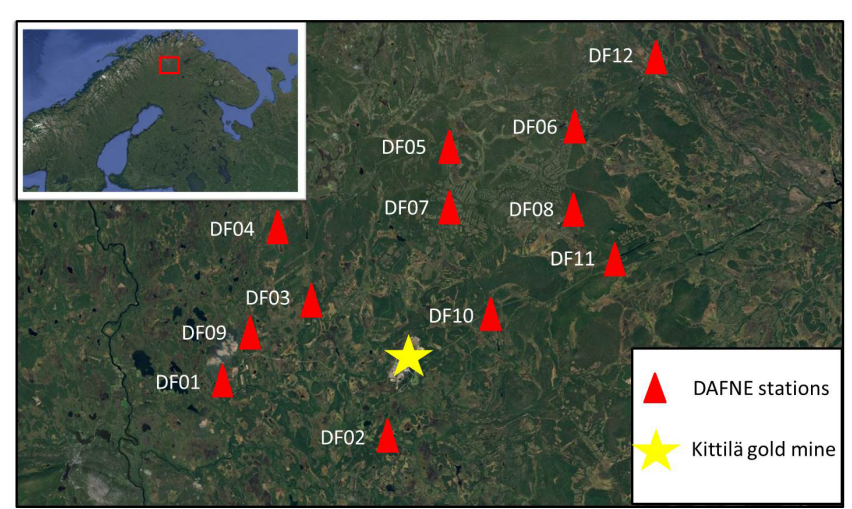

Figure 1. Position of the DAFNE temporary array on the geographical map.

damage zones (FDZs) which arise along the fault as a result of brittle deformation and cracking in rock in response to stress (Chester and Logan, 1986; Shipton and Cowie, 2003). Kim et al. (2004) demonstrated that damage zones show very similar geometries across a wide range of scales and fault types, including strike-slip, normal and thrust faults. These fault damage zones are mechanically weaker than surrounding rock and they can be detected as zones of low seismic velocities. Some recent investigations of FDZs produced by large earthquakes have demonstrated that the width of them can vary from several dozen metres to $1-2 \mathrm{~km}$ (Vidale and Li, 2003; Cochran et al., 2009). It is still debatable whether FDZs persist over a full earthquake cycle, which may last hundreds to thousands of years (Cochran et al., 2009) or the FDZs are healing during the years or decades following a main shock (Crone et al., 2003; Vidale and Li, 2003).

The question of longevity of faults is particularly important in investigating the continental intraplate seismicity regime (Stein, 2007). It is known that most such earthquakes can be related to detected fault zones, but continents contain many such features, of which only few are active. As suggested by Stein (2007) and McKenna et al. (2007), longlived, wide and mechanically weak damage zones concentrate intraplate strain release; hence, hypocentres of future earthquakes would be located along these zones. However, if the damage zones are healed after the major shock, and are not significantly weaker than surrounding, then the intraplate seismicity would be a transient phenomenon that migrates among many fossil weak zones. That is why study of damage zones of the faults proved to be not active during historical time may provide new information about the intraplate seismicity phenomenon.

In our study we address the problem using an example of the Suasselkä postglacial fault located in northern Fennoscandia (Fig. 2). Postglacial (PG) faults there were formed during the last stages of the Weichselian glaciation (ca. 9000-15000 years BP), when reduced ice load and relaxation of accumulated tectonic stress resulted in rapid up-

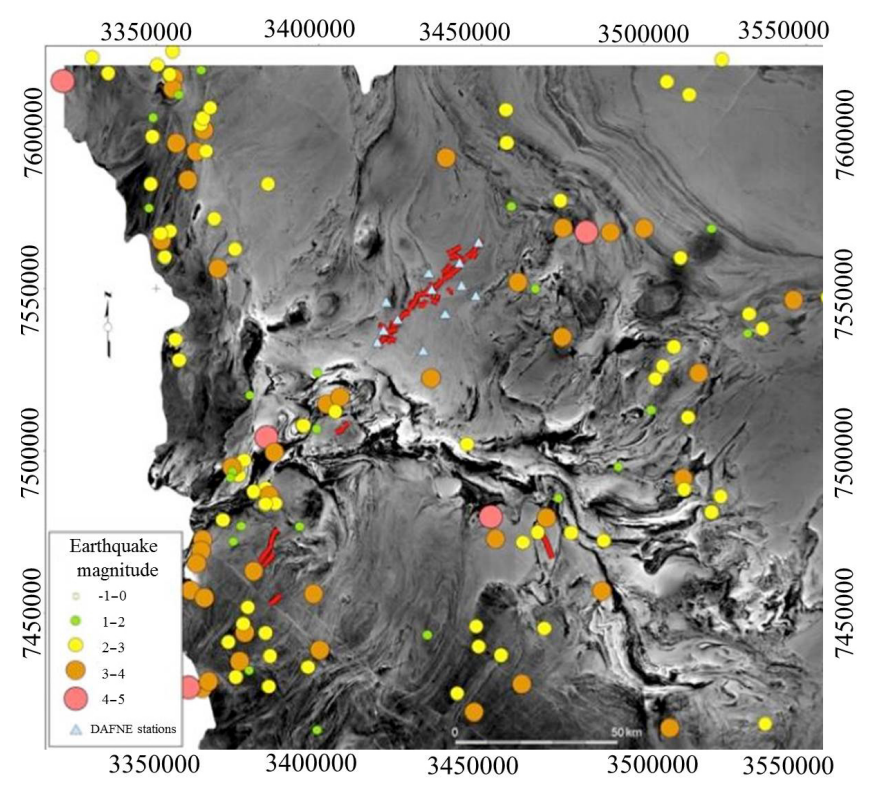

Figure 2. Position of DAFNE temporary array (blue triangles) on the aeromagnetic field map of Finland. Epicentres of local earthquakes detected by regional seismic networks in Fennoscandia prior to DAFNE/FINLAND experiment are shown by circles with size proportional to the magnitude of the event. Postglacial faults in the area are shown by red lines. The coordinate system is the Finnish National Coordinate System (KKJ).

lift in Fennoscandia and large-magnitude earthquakes with $M_{w}$ of 7-8.2 (Wu et al., 1999; Olesen et al., 2004; Kukkonen et al., 2010). The length of the PGFs may vary from 2 to $150 \mathrm{~km}$ and the maximum height of the fault scarps from 1 to $12 \mathrm{~m}$, and up to $30 \mathrm{~m}$ in the extreme cases (see compilation in Olesen et al., 2004). However, postglacial faulting is not confined to northern Fennoscandia, but has also been reported in northernmost Germany (Brandes et al., 2012) and central parts of Sweden and Finland (Malehmir et al., 2016; Mikko et al., 2015; Palmu et al., 2015; Juhlin and Lund, 2011; Juhlin et al., 2010).

The Suasselkä postglacial fault (SPGF) of total length of $48 \mathrm{~km}$ is the longest PGF in Finland with a strike of $35-50^{\circ}$ and scarp of $0-3 \mathrm{~m}$. Geomorphological studies revealed multiple and differently oriented surface signatures of the SPGF (Fig. 2). The fault zone has been studied using magnetic and electromagnetic measurements by Paananen (1987) and Kuivamäki et al. (1998), who suggested that the fault dips southeastward. The sense of motion was thrusting from southeast. The origin of the structure is probably much older than postglacial as suggested by the coincidence of the fault scarp with magnetic anomalies of the Palaeoproterozoic bedrock. The southeastern part of the fault is located in pre-existing fracture zone in the southeast, whereas existence of the oldest structure in the northwest remains uncertain. Based on the radiocarbon-dated buried organic materials, the time frame of fault activity ranges from 9730 to 5055 


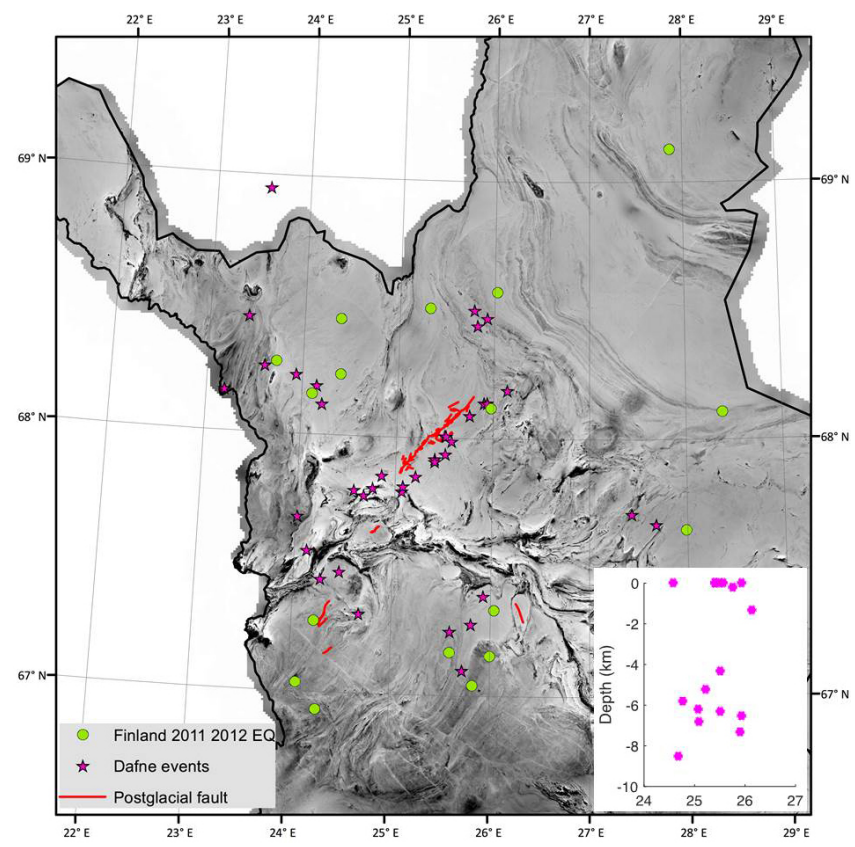

Figure 3. Epicentres of local earthquakes (magenta stars) identified from recordings of the DAFNE/FINLAND temporary during September 2011-May 2012 shown on the aeromagnetic map of Finland. Epicentres of local earthquakes detected by regional seismic networks in Fennoscandia during September 2011-May 2012 are shown with green dots. Red lines indicate postglacial faults in the area. Right corner inset shows depth distribution of the events originating from the SPGF area. Precision of hypocentre coordinate determination is of the order of $2-5 \mathrm{~km}$. The average error of depth determination is about $3-4 \mathrm{~km}$.

cal. years BP (Sutinen et al., 2014). The reprocessed seismic data along several reflection profiles crossing the fault area (Ahmadi et al., 2015) demonstrated the complex structure of the fault area down to a depth of $2-3 \mathrm{~km}$, with two sets of segmented and discontinuous dipping reflectors.

In our study we investigate the inner structure of the SPGF using distribution of hypocentres of local seismic events and analysis of ambient seismic noise, recorded by the temporary DAFNE array. The ambient seismic noise analysis has been used recently by Hillers et al. (2014) in order to investigate the inner structure and properties of Calico Fault Zone in eastern California. Zigone et al. (2015) applied ambient seismic noise tomography in order to study the Southern California Plate Boundary Region.

\section{Data}

The main objective of the DAFNE/FINLAND seismic passive experiment was to answer two major questions: (a) is the Suasselkä postglacial fault (SPGF) still seismically active, and (b) if it is active, what is the geometry of its seismogenic zone and the depth to it? The project was initiated by several organizations in Finland (Geological Survey of Finland, Sodankylä Geophysical Observatory of the University of Oulu and Institute of Seismology of the University of Helsinki). The main purpose of the field experiment was to install an array of autonomous seismic stations in the target area of the SPGF in order to collect continuous seismic data for the period of September 2011-May 2013.

Selection of the DAFNE sites was done in August 2011. Four sites with the permanent electric power supply were found in the vicinity of the target area (SPGF). The other eight sites were selected taking into consideration surface position of the fault and the possible dip of the fault to the southeast. In the first part of September 2011 the sites were prepared for installation and autonomous seismic recording instruments were installed to the sites during the second part of September 2011. Coordinates of all stations of the DAFNE array and description of the instrumentation, used in the experiment, are given in Table 1. The instruments were provided by the Institute of Seismology of the University of Helsinki and by the Sodankylä Geophysical Observatory. Location of stations of the DAFNE array is shown in Fig. 1.

During the data acquisition period, all the stations were regularly (once per 2 months on average) served by two staff members of the Sodankylä Geophysical Observatory. The regular service included changing of batteries and media and basic data quality control. Raw continuous data files from temporary stations of the DAFNE array were copied to the data server of the SGO in their original formats. The main steps for data pre-processing included applying time corrections, conversion to the miniSEED format and merging the data files into miniSEED files of $24 \mathrm{~h}$ length using IRIS PASSCAL software for processing and visualization of seismological data (http://www.iris.edu/manuals/SEEDManual_ V2.4.pdf). Analysis of continuity of the data and estimation of noise level at the sites was performed after each field trip. Generally, the noise level was higher during daytime, and seismograms, recorded during the daytime, were seriously contaminated by signals from production blasts in numerous mines in northern Sweden, Finland and Russia. Major problems were detected at stations DF10 and DF07, where the high noise level was due to technical problems with sensors and cables.

\section{Detection and location of seismic events}

At the beginning of the data analysis, we compiled a preliminary list of local seismic events using monthly seismic bulletins, published by the Institute of Seismology of the University of Helsinki (FENCAT: http://www.seismo.helsinki. fi/english/bulletins/index.html). The criteria for events selection were coordinates of epicentres (from 67.5 to $69^{\circ} \mathrm{N}$ and from 23 to $28^{\circ} \mathrm{E}$ ) and the time frame corresponding to the DAFNE data acquisition period. The epicentres of these events are shown in Fig. 3. As can be seen, regional perma- 
Table 1. Information about seismic stations of the DAFNE/FINLAND temporary array.

\begin{tabular}{|c|c|c|c|c|c|c|c|c|c|c|c|c|c|}
\hline \multirow[b]{2}{*}{ Name } & \multirow[b]{2}{*}{ Location } & \multicolumn{3}{|c|}{ Coordinates } & \multicolumn{5}{|c|}{ Operation started } & \multirow[b]{2}{*}{ Group } & \multirow[b]{2}{*}{$\begin{array}{l}\text { Sensor } \\
\text { type }\end{array}$} & \multirow[b]{2}{*}{ Logger } & \multirow[b]{2}{*}{$\begin{array}{l}\text { Sampling } \\
\text { rate (sps) }\end{array}$} \\
\hline & & Lat. & Long. & $\begin{array}{r}\text { Height } \\
(\mathrm{m})\end{array}$ & Day & Month & Year & Hour & Min. & & & & \\
\hline DF01 & Rautuskylä & 67.8758 & 25.0514 & 241 & 13 & 9 & 2011 & 7 & 17 & Oulu & $\begin{array}{l}\text { Trillium } \\
\text { compact }\end{array}$ & PR6-24 & 100 \\
\hline DF02 & Lehto & 67.8566 & 25.3862 & 227 & 23 & 9 & 2011 & 13 & 50 & Oulu & $\begin{array}{l}\text { Trillium } \\
\text { compact }\end{array}$ & $\begin{array}{l}\text { Reftek } \\
130\end{array}$ & 100 \\
\hline DF03 & Kapsajoki & 67.9403 & 25.1931 & 244 & 16 & 9 & 2011 & 14 & 7 & $\begin{array}{l}\text { Helsinki+ } \\
\text { Oulu }\end{array}$ & $\begin{array}{l}\text { Lennartz } \\
\text { 3-D lite }\end{array}$ & $\begin{array}{l}\text { Reftek } \\
130\end{array}$ & 100 \\
\hline DF04 & Kiimalaki & 97.9886 & 25.1042 & 274 & 16 & 9 & 2011 & 15 & 22 & Oulu & Mark L4a & $\begin{array}{l}\text { Reftek } \\
130\end{array}$ & 100 \\
\hline DF05 & Outa-Perttunen & 68.0715 & 25.4131 & 302 & 15 & 9 & 2011 & 12 & 30 & Oulu & Mark L4a & $\begin{array}{l}\text { Reftek } \\
130\end{array}$ & 100 \\
\hline DF06 & Mietrikkilehto & 68.1015 & 25.6388 & 314 & 15 & 9 & 2011 & 9 & 47 & Helsinki & $\begin{array}{l}\text { Lennartz } \\
\text { 3-D lite }\end{array}$ & $\begin{array}{l}\text { Reftek } \\
130\end{array}$ & 100 \\
\hline DF07 & Suasselkä & 68.0262 & 25.4365 & 286 & 16 & 9 & 2011 & 6 & 34 & Helsinki & $\begin{array}{l}\text { Lennartz } \\
\text { 3-D lite }\end{array}$ & $\begin{array}{l}\text { Reftek } \\
130\end{array}$ & 100 \\
\hline DF08 & Arabiankangas & 68.0395 & 25.6588 & 326 & 15 & 9 & 2011 & 7 & 51 & Helsinki & $\begin{array}{l}\text { Lennartz } \\
\text { 3-D lite }\end{array}$ & $\begin{array}{l}\text { Reftek } \\
130\end{array}$ & 100 \\
\hline DF09 & Salo & 67.9091 & 25.0926 & 227 & 14 & 9 & 2011 & 7 & 10 & Oulu & $\begin{array}{l}\text { Trillium } \\
\text { compact }\end{array}$ & PR6-24 & 100 \\
\hline DF10 & Tepsänjänkkä & 67.9595 & 25.5397 & 271 & 15 & 9 & 2011 & 14 & 40 & Helsinki & $\begin{array}{l}\text { Lennartz } \\
\text { 3-D lite }\end{array}$ & $\begin{array}{l}\text { Reftek } \\
130\end{array}$ & 100 \\
\hline DF11 & Rajalompolontie & 68.0110 & 25.7622 & 340 & 17 & 9 & 2011 & 7 & 21 & Helsinki & $\begin{array}{l}\text { Lennartz } \\
\text { 3-D lite }\end{array}$ & $\begin{array}{l}\text { Reftek } \\
130\end{array}$ & 100 \\
\hline DF12 & Pokka & 68.1596 & 25.7760 & 282 & 13 & 9 & 2011 & 14 & 36 & Oulu & $\begin{array}{l}\text { Trillium } \\
\text { compact }\end{array}$ & $\begin{array}{l}\text { SeisCom } \\
\mathrm{P}\end{array}$ & 100 \\
\hline
\end{tabular}

nent seismic networks detected no natural events from the SPGF area. This can be partly explained by large distances between the fault and existing permanent seismic stations. The second problem for detection of natural seismic events in northern Finland is a huge number of production and development blasts originating from numerous underground and open pit mines. The DAFNE/FINLAND array recorded up to 100 of such blasts per day from northern Sweden, Russia and Finland. Due to this, it was not possible to use a routine LTA/STA analysis for automatic event detection. Therefore, the manual data analysis was used. The continuous data were accessed and reviewed with the Seismic Handler Motif (SHM) program package (http://www.seismic-handler.org/ portal).

As a first step, we analysed all the continuous data for the period of September 2011-October 2011 and relocated all local events seen in the DAFNE data. Then, we compiled a dataset of waveforms of explosions from the mines outside the target area and detected typical blasting time intervals for these mines. This dataset was used to exclude such events from further analysis. This was a necessary data processing step, because about $30-50 \%$ of all such explosions are not included in the FENCAT bulletin and other regional bulletins.

The continuous data were filtered using the Butterworth third-order $2-40 \mathrm{~Hz}$ band pass filter and waveforms were analysed using SMH software. In total, 1188 events in (a)

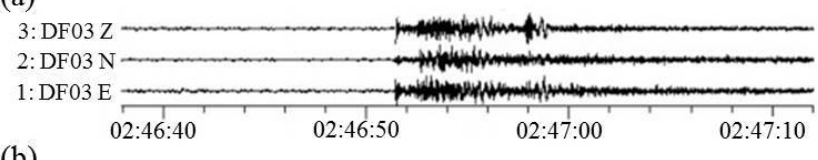

(b)

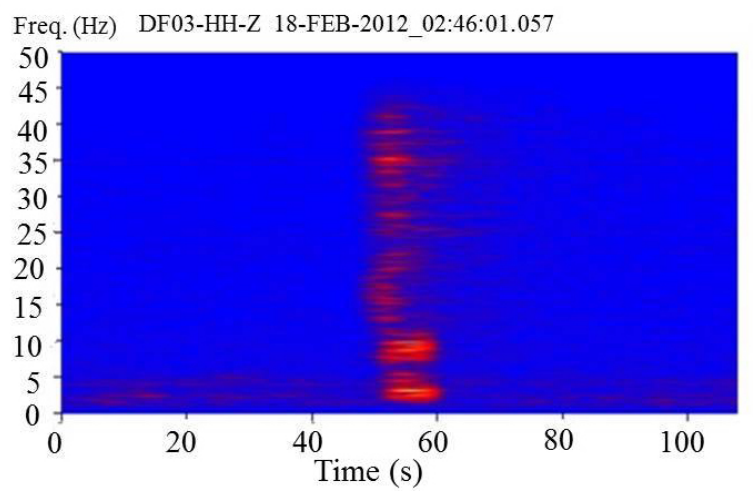

Figure 4. (a) An example of waveforms of production blast in Kittilä Mine recorded by DF03 station. (b) An example of a spectrogram of the same event.

September 2011-October 2011 were analysed and relocated using the DAFNE array data.

For relocation we used the LocSAT seismic event location program (Bratt, 1988) and manually picked first arrivals of $\mathrm{P}$ and $\mathrm{S}$ waves. The first arrivals of $\mathrm{P}$ waves were picked on $Z$ component of the data filtered by the Butterworth third- 
(a)

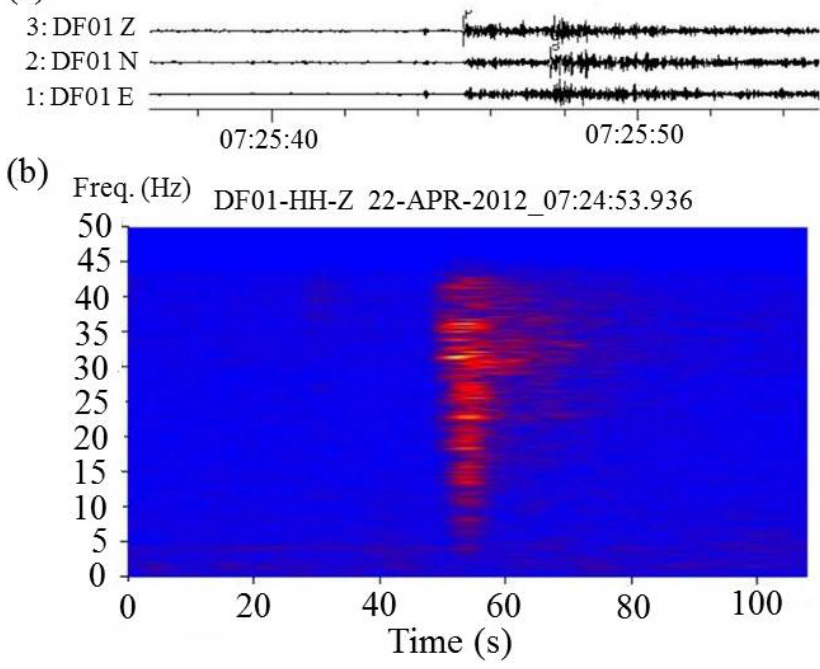

Figure 5. (a) Waveforms of a local earthquake on 22 April 2012, 07:25:41 UT, at $67.8^{\circ} \mathrm{N}, 24.76^{\circ} \mathrm{E}$, depth $5.8 \mathrm{~km}$ recorded by DF01 station. (b) The spectrogram of the same event.

order $2-40 \mathrm{~Hz}$ band pass filter. The first arrivals of $\mathrm{S}$ waves were picked either on horizontal $\mathrm{E}$ or $\mathrm{N}$ component filtered by the Butterworth third-order $2-6 \mathrm{~Hz}$ band pass filter, depending on the number of traces in which the same signal was seen.

The distance between epicentre and stations of the array is less than $60 \mathrm{~km}$ for events, originating from the target area. In this case, the first arrivals of $\mathrm{P}$ and $\mathrm{S}$ wave correspond to direct Pg and Sg waves, refracting in the upper crust and the LocSAT procedure provides hypocentre coordinates with precision satisfactory for event detection.

In order to test the precision of the location procedure, we used blasts originating from the Kittilä gold mine. These blasts occurred inside known blasting time windows and have similar waveforms. Information about time windows for production and development blasting time was kindly provided by Engineering Superintendent André van Wageningen (personal communication, 2012) of Agnico-Eagle Kittilä Mine.

The hypocentres of selected blasts, obtained after relocation, were concentrated inside the mining area, which is about $5 \mathrm{~km}$ long and $2 \mathrm{~km}$ wide (www.agnicoeagle.com), with depths varying from 0 to $1 \mathrm{~km}$. This location precision is satisfactory for proper detection of events originating from the fault area. As a result of this preliminary analysis, we distinguished two types of events, originating from our target area, but having different waveforms:

1. blasts originating from the Kittilä mine (Fig. 4);

2. events originating from the SPGF area and its surrounding, which could be of natural origin (Fig. 5).
Table 2. List of seismic events in the area of Suasselkä postglacial fault detected by the DAFNE seismic array.

\begin{tabular}{|c|c|c|c|c|c|c|c|c|}
\hline Year & Month & Day & Hour & Min & $\mathrm{Sec}$ & $\begin{array}{r}\text { Lat } \\
\text { (deg.) }\end{array}$ & $\begin{array}{r}\text { Long } \\
\text { (deg.) }\end{array}$ & $\begin{array}{r}\text { Depth } \\
(\mathrm{km})\end{array}$ \\
\hline 2011 & 9 & 28 & 22 & 8 & 59 & 67.85 & 24.86 & 12.5 \\
\hline 2011 & 10 & 8 & 22 & 26 & 13 & 67.31 & 24.67 & 5.2 \\
\hline 2011 & 11 & 17 & 1 & 18 & 10 & 68.01 & 25.5 & 0 \\
\hline 2011 & 11 & 17 & 1 & 18 & 10 & 68.01 & 25.51 & 4.3 \\
\hline 2011 & 12 & 3 & 18 & 5 & 52 & 68.45 & 23.41 & 1 \\
\hline 2011 & 12 & 7 & 22 & 36 & 16 & 67.94 & 25.51 & 6.3 \\
\hline 2011 & 12 & 9 & 3 & 47 & 51 & 68.47 & 25.92 & 7.5 \\
\hline 2011 & 12 & 10 & 5 & 47 & 18 & 68.26 & 23.6 & 3.1 \\
\hline 2011 & 12 & 12 & 12 & 50 & 23 & 67.85 & 25.21 & 5.2 \\
\hline 2011 & 12 & 24 & 4 & 52 & 44 & 67.25 & 25.59 & 4.9 \\
\hline 2011 & 12 & 24 & 19 & 42 & 1 & 68.44 & 25.82 & 7.5 \\
\hline 2011 & 12 & 31 & 3 & 24 & 27 & 67.79 & 24.58 & 0 \\
\hline 2012 & 1 & 7 & 7 & 25 & 40 & 67.79 & 25.07 & 6.2 \\
\hline 2012 & 1 & 12 & 0 & 15 & 19 & 67.55 & 24.12 & 8.6 \\
\hline 2012 & 1 & 17 & 3 & 22 & 39 & 68.12 & 24.21 & 17 \\
\hline 2012 & 1 & 18 & 21 & 44 & 15 & 68.14 & 25.93 & 6.5 \\
\hline 2012 & 1 & 20 & 5 & 36 & 31 & 68.14 & 25.9 & 7.3 \\
\hline 2012 & 1 & 23 & 16 & 36 & 47 & 67.1 & 25.72 & 6.5 \\
\hline 2012 & 1 & 23 & 23 & 24 & 23 & 67.81 & 25.08 & 6.8 \\
\hline 2012 & 2 & 11 & 18 & 44 & 4 & 67.99 & 25.57 & 0 \\
\hline 2012 & 2 & 18 & 0 & 33 & 4 & 68.14 & 25.93 & 0 \\
\hline 2012 & 2 & 19 & 1 & 24 & 20 & 67.77 & 24.68 & 8.5 \\
\hline 2012 & 3 & 4 & 14 & 22 & 44 & 67.92 & 25.4 & 0 \\
\hline 2012 & 3 & 4 & 23 & 27 & 31 & 67.92 & 25.4 & 0 \\
\hline 2012 & 3 & 19 & 23 & 49 & 17 & 68.23 & 23.93 & 2.5 \\
\hline 2012 & 4 & 9 & 1 & 3 & 41 & 68.19 & 24.15 & 14.2 \\
\hline 2012 & 4 & 15 & 15 & 39 & 29 & 67.47 & 24.46 & 4.6 \\
\hline 2012 & 4 & 17 & 16 & 0 & 19 & 68.19 & 26.14 & 1.3 \\
\hline 2012 & 4 & 18 & 20 & 47 & 32 & 67.71 & 27.43 & 9.5 \\
\hline 2012 & 4 & 20 & 11 & 28 & 9 & 68.09 & 25.75 & 0.2 \\
\hline 2012 & 4 & 22 & 7 & 25 & 41 & 67.8 & 24.77 & 5.8 \\
\hline 2012 & 4 & 24 & 8 & 58 & 5 & 68.16 & 23.19 & 7.8 \\
\hline 2012 & 4 & 26 & 16 & 38 & 51 & 67.68 & 24.01 & 2.4 \\
\hline 2012 & 4 & 30 & 4 & 15 & 1 & 68.95 & 23.57 & 0 \\
\hline 2012 & 5 & 1 & 9 & 29 & 39 & 67.91 & 25.4 & 0 \\
\hline 2012 & 5 & 8 & 22 & 38 & 34 & 67.44 & 24.27 & 11.1 \\
\hline 2012 & 5 & 14 & 22 & 10 & 11 & 67.28 & 25.8 & 7.1 \\
\hline 2012 & 5 & 16 & 10 & 55 & 31 & 67.39 & 25.92 & 0 \\
\hline 2012 & 5 & 21 & 14 & 16 & 24 & 68.5 & 25.78 & 2.1 \\
\hline 2012 & 5 & 25 & 18 & 27 & 58 & 67.67 & 27.68 & 4.7 \\
\hline
\end{tabular}

The waveforms of these events were used in further manual analysis of continuous data for the period until 31 May 2012. Totally, the DAFNE network recorded 10230 local events during September 2011-May 2012. From this amount, we selected 40 events with the waveforms similar to those of the group 2 and located them, using manually picked first arrivals of $\mathrm{P}$ and $\mathrm{S}$ waves and the LocSAT software. Additional control on discriminating natural events from blasts in Kittilä gold mine was performed using analysis of waveforms spectra (Glitterman and van Eck, 1993; Glitterman and Shapira, 1998). Coordinates of hypocentres of events, identified as natural ones, are presented in Table 2 and their epicentres are shown in Fig. 3. In our study precision of hypocentre coordinate determination by LocSat is usually of the order of $2-5 \mathrm{~km}$ and the depth of hypocentres of local earthquakes varies from about 2 to $15 \mathrm{~km}$, with an average error of about 3-4 km. Hypocentres of events, originating from the 
(a)
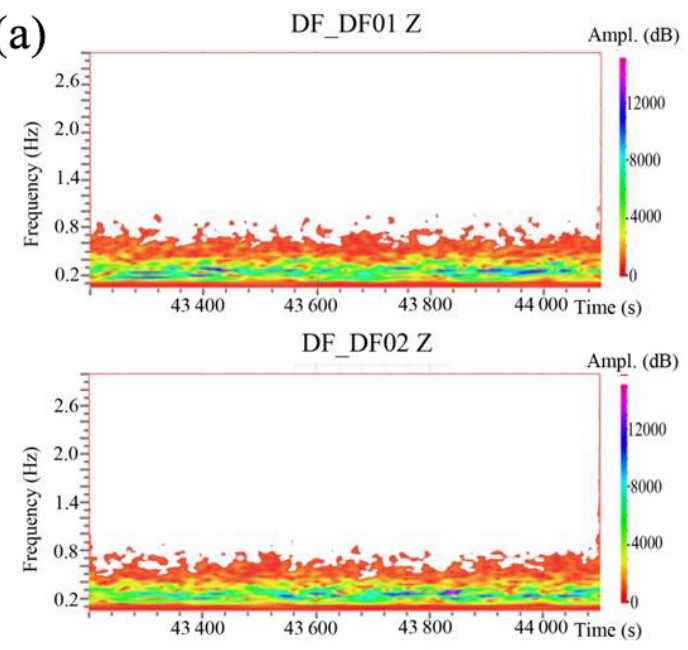

(b)
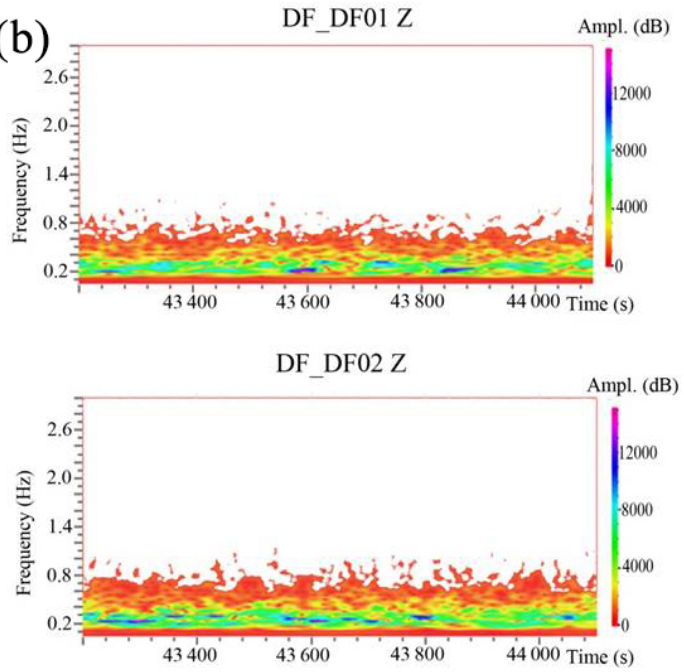
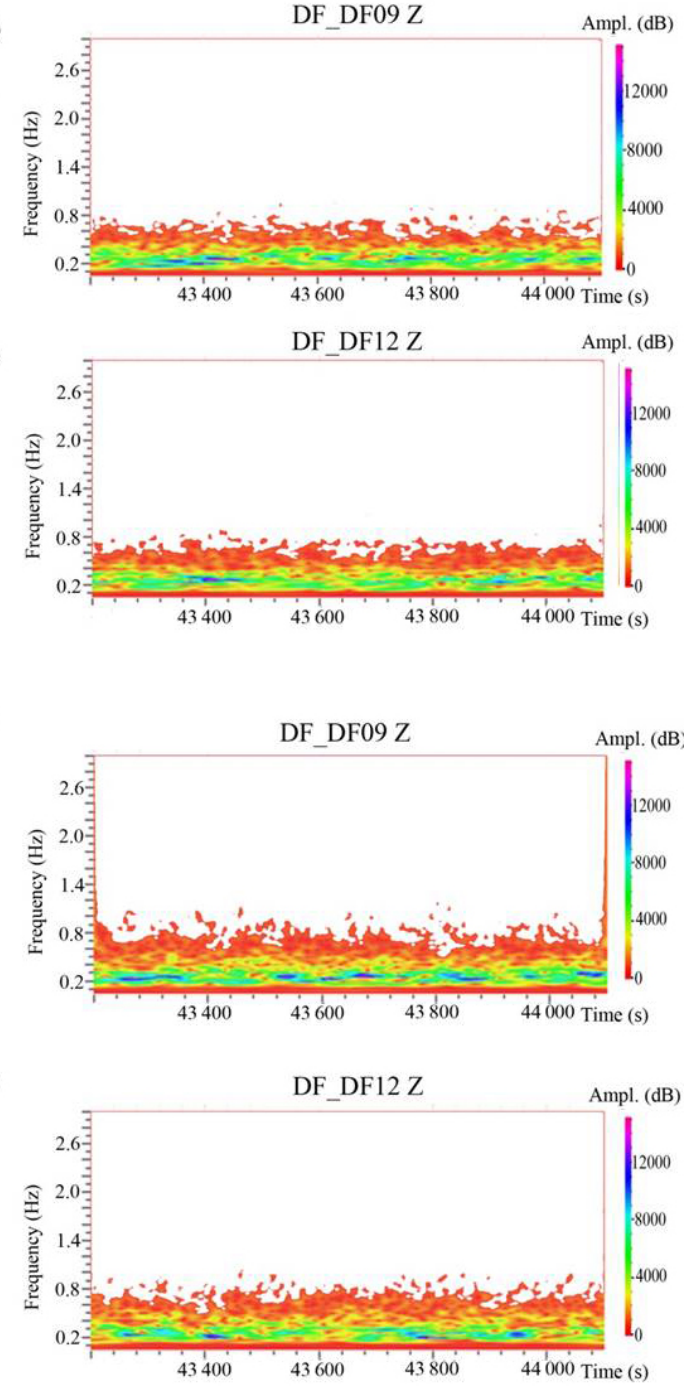

Figure 6. Examples of typical ambient noise spectrograms estimated for the low-frequency band (0.1-3 Hz). (a) During weekend and (b) during the working week.

SPGF, have depths up to $8.5 \mathrm{~km}$. As can be seen, epicentres of many local earthquakes recorded by DAFNE/FINLAND array show good spatial coincidence with the Suasselkä postglacial fault. This indicates that the fault zone is still seismically active. Generally, the epicentres are shifted to the southeast from the surface position of the fault. This agrees with the previous studies by Paananen (1987) and Kuivamäki et al. (1998), who suggested that the fault dips southeast.

\section{Ambient noise analysis}

Analysis of empirical Green's functions (EGFs), estimated from ambient seismic noise, has been widely used in order to study seismic velocities in the subsurface (see Shapiro and Campillo, 2004; Shapiro et al., 2005; Campillo, 2006). Poli et al. (2012a, b, 2013) applied analysis of EGFs to retrieve body waves reflected from the Moho and upper mantle discontinuities and to estimate the 3-D S-wave velocity of the upper crust of northern Finland. In our study we apply the procedure described in Poli et al. (2012b, 2013) in order to estimate EGFs from continuous recordings of vertical component of all stations of the DAFNE array. The functions are then used in order to estimate seismic velocities in the uppermost crust of the SPGF area.

\subsection{Analysis of spectrograms of the ambient noise}

Some stations of the DAFNE temporary network were installed in the sites with a high level of anthropogenic noise (for example, station DF02 was installed near the Kittilä Gold mine; Fig. 1). Such noise is not propagating to large distances from the noise source, and this may cause a decline in the quality of EGFs. For identification of anthro- 
(a)
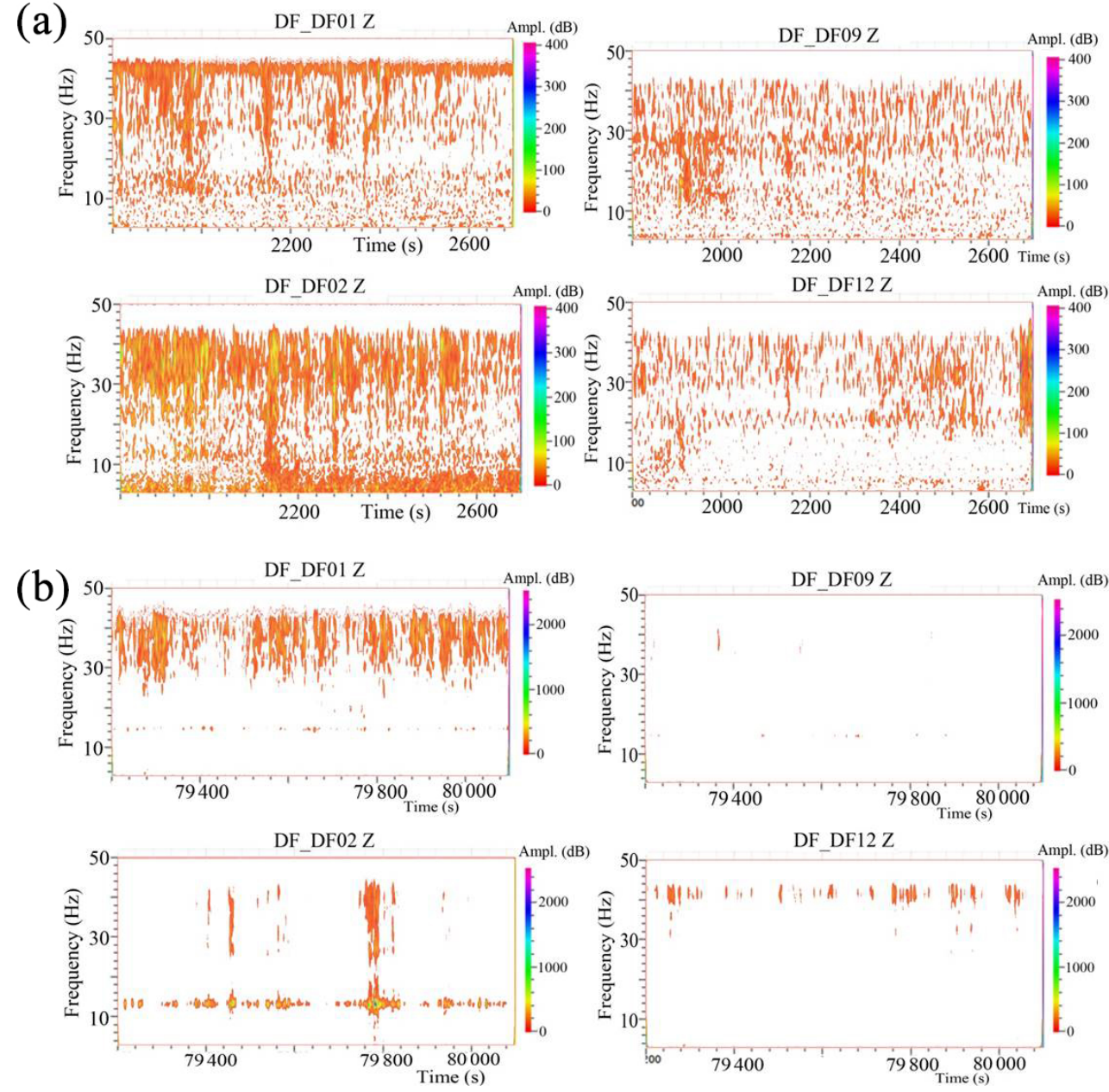

Figure 7. Examples of typical ambient noise spectrograms estimated for the high frequency band (3-50 Hz). (a) During the weekend and (b) during the working week.

pogenic noise on seismograms and selection of frequency band for filtering of the input data before cross-correlation, we used analysis of spectrograms. These spectrograms were estimated from continuous data recorded by stations closest to the mine (DF01, DF02, and DF09) and by the most distant station from the mine (DF12). We studied high-frequency and low-frequency parts of spectrograms separately and also compared the spectrograms calculated for weekends and for the working week. The examples are shown in Fig. 6a and b, respectively. As can be seen, all the spectrograms are identical in the frequency band of $0.1-3 \mathrm{~Hz}$ and characteristics of the noise in this frequency band do not depend on day of the week and location of stations with respect to the mine.

If the high frequencies are considered, one can see stable noise in the frequency band of $\sim 13-14 \mathrm{~Hz}$ for workday (Fig. 7b). This noise was recorded by stations in the vicinity of the mine (DF01, DF02, DF09), but it was not registered by the station most distant from the mine (DF12). Therefore, it is anthropogenic noise from the mine. It is worth noting that

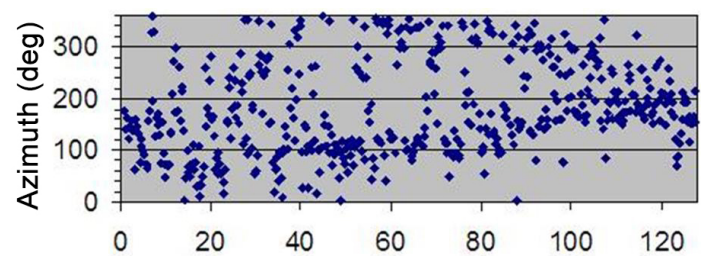

Figure 8. Azimuthal distribution of ambient noise sources during time periods from 1 January to 30 April 2012 and from 10 to 31 December 2012 estimated by beam forming in the time domain. Numbers on the abscissa axis correspond to the relative day numbers (see the text for additional explanation).

station DF12 was installed near the river, and thus the stable amplitude maximum at a frequency of about $42 \mathrm{~Hz}$ is most probably the noise of the river (Fig. 6b).

Thus, we applied filtering in the band of $0.1-1 \mathrm{~Hz}$ for all input seismograms before computation of EGFs. 

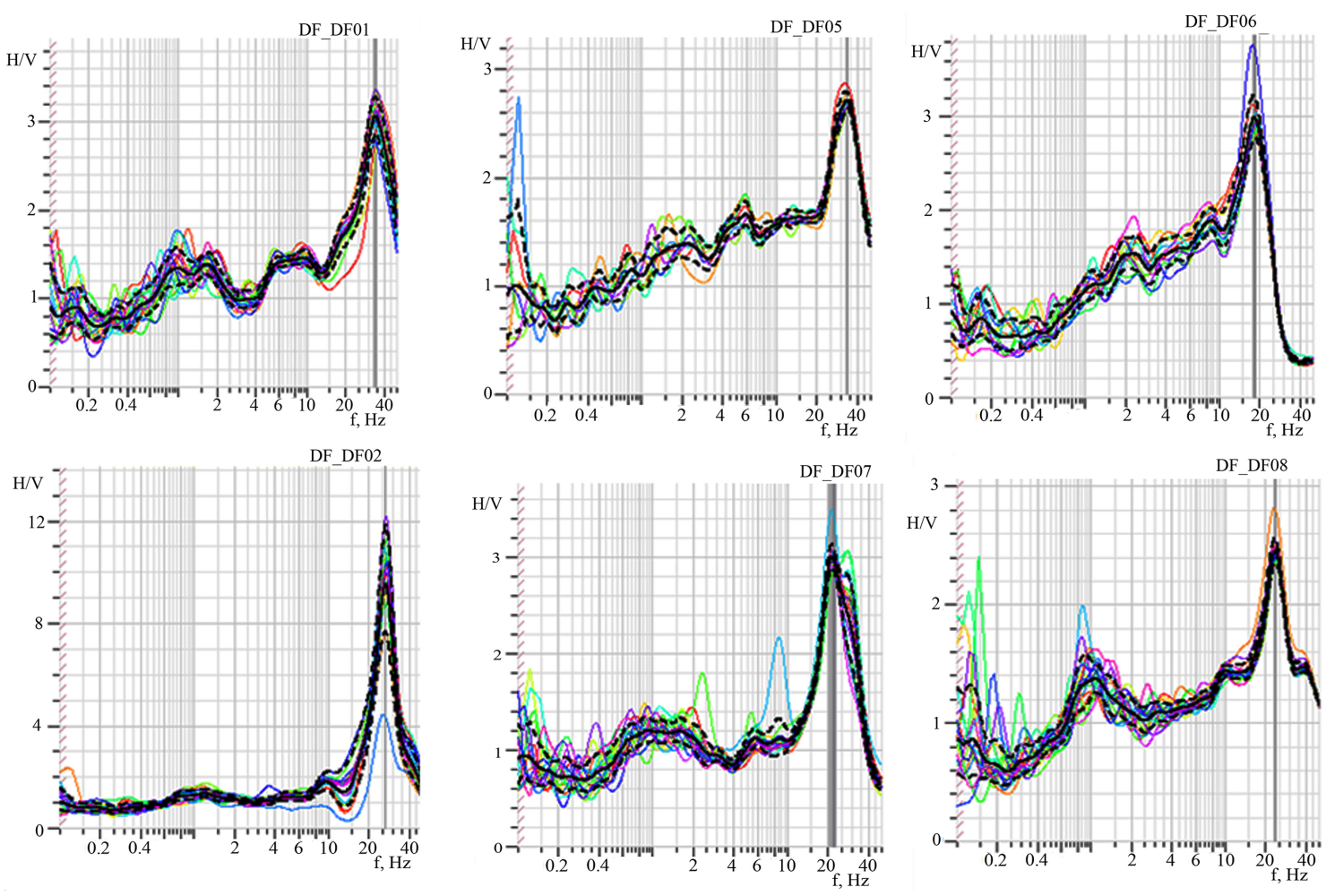

Figure 9. Results of horizontal-to-vertical (H/V) analysis for selected stations of the DAFNE array. The resonance frequency is marked by the grey bar, with width corresponding to error bar.

\subsection{Analysis of azimuthal distribution of noise sources}

Analysis of azimuthal distribution of ambient noise sources during the data acquisition period is an important part of data preparation for EGFs calculation, as the algorithm of their calculation is strongly dependent on directivity of noise sources. The algorithm is simpler if the noise sources have uniform azimuthal distribution. There are some methods of calculation of azimuthal distribution, such as f-k analysis (Neiddell and Taner, 1971; Douze and Laster, 1979) and beam forming (see Rost and Thomas, 2002; Schweizer et al., 2012). The configuration of the DAFNE array unfortunately does not allow for use of $\mathrm{f}-\mathrm{k}$ analysis. That is why we analysed the azimuthal noise distribution using beam forming in the time domain. For this we calculated about 5000 EGFs between station DF09 and every other station of the DAFNE array. Six segments per day with a duration of $1 \mathrm{~h}$ were selected for each day from 1 January to 30 April 2012 and from 10 to 31. December 2012. During these time periods all the stations of the array were recording data. Surface wave parts of Green's functions were calculated from selected segments, which were band-pass-filtered in the band of $0.1-1 \mathrm{~Hz}$. The result is shown in Fig. 8.

As one can see, during January and February 2012 (days $0-50)$ the ambient noise was recorded from various directions, with prevailing azimuth of $0-200^{\circ}$. From 1 March
2012 onwards the prevailing azimuths are of approximately 100 and $350-360^{\circ}$, and this tendency is slightly changing during March (days approximately 50-80) and April (days approximately $80-110$ ). In December the prevailing azimuths are approximately $100-210^{\circ}$. The observed changes in azimuthal distribution of noise sources may be caused by reduction of marine microseisms during winter months because the range of $300-360^{\circ}$ corresponds to azimuths to the seashore in the north. This distribution is necessary to take into account when interpreting EGF.

\subsection{Horizontal-to-vertical (H/V) analysis of the ambient noise}

The bedrock in our study area is covered by a thin (up to several dozen metres) layer of Quaternary deposits developed during the late Weichselian glaciation. In our study, we applied H/V analysis of ambient noise (Nakamura, 1989; SESAME H/V User Guidelines, 2005) in order to estimate thickness of the sedimentary layer. It was necessary to do this prior to calculation of velocity models using inversion of EGFs because low velocities in this layer can affect inversion results.

We applied the $\mathrm{H} / \mathrm{V}$ analysis procedure implemented into Geopsy software (www.geopsy.org) to ambient seismic noise, recorded by selected DAFNE stations during winter and summer months. We used time segments selected from 
(a)

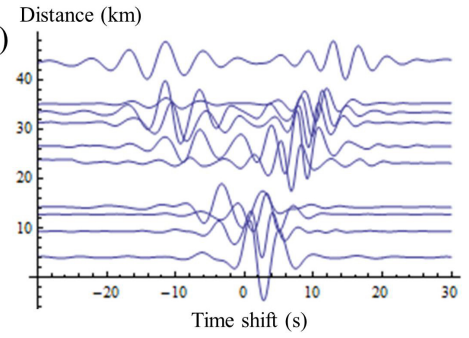

(b)

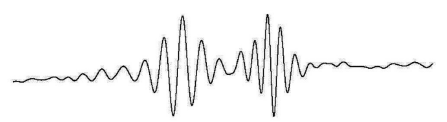

(c)

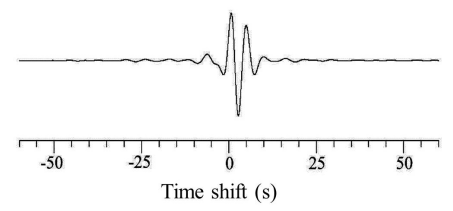

Figure 10. (a) Empirical Green's functions calculated between station DF01 and all other stations of the DAFNE array. (b) EGF calculated for stations with the largest interstation distance (DF01 and DF12). (c) EGF calculated for stations with the smallest interstation distance (DF01 and DF09).

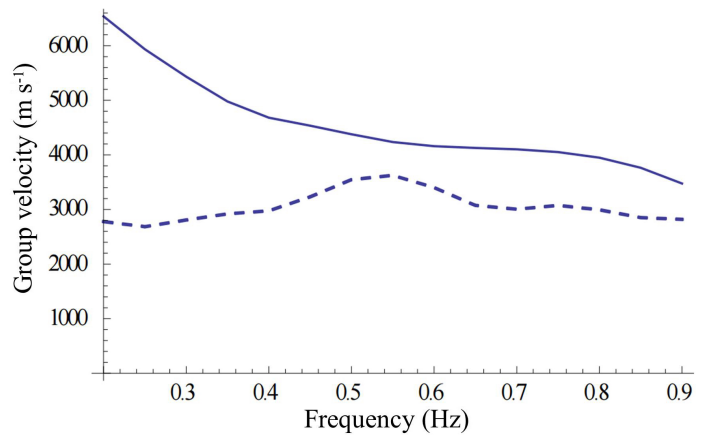

Figure 11. Example of dispersion curves corresponding to the fundamental and first-order higher mode of Rayleigh wave estimated from EGFs. The dashed line denotes the fundamental mode and the solid line denotes the first higher mode.

parts of recordings without anthropogenic noise with duration of $30 \mathrm{~min}$. Results obtained for winter and summer time were identical. Fig. 9 demonstrates an example of the result of $\mathrm{H} / \mathrm{V}$ analysis for some selected stations.

As can be seen from Fig. 9, the resonance frequency is between 20 and $40 \mathrm{~Hz}$ for all the data considered. From petrological data for sedimentary rocks (Gebrande et al., 1982; Kaikkonen, 2007), the S-wave velocities are about 250 $350 \mathrm{~m} \mathrm{~s}^{-1}$ and P-wave velocities are about $500-700 \mathrm{~m} \mathrm{~s}^{-1}$ in our study area. Therefore, the maximum thickness of the sedimentary layer in the study area can be estimated as $5 \mathrm{~m}$.

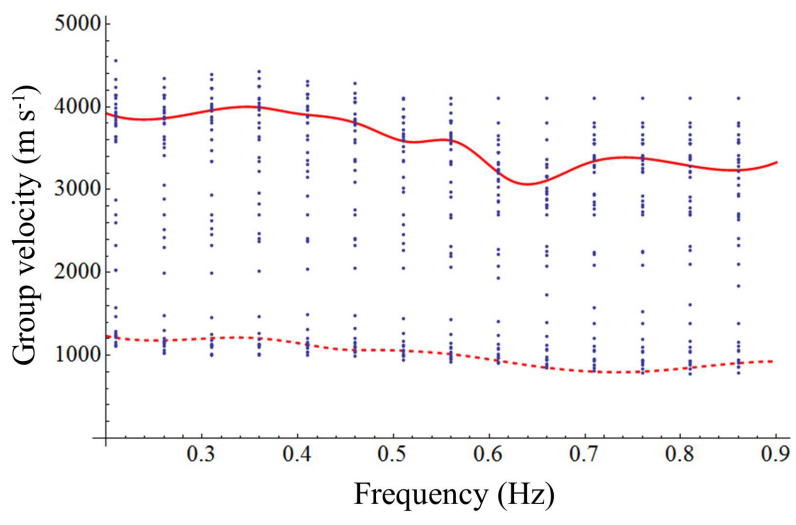

Figure 12. A set of dispersion curves estimated from all EGFs of DAFNE array (blue dots) that demonstrates their bimodal distribution. Averaged dispersion curves calculated for two groups of seismic station pairs (see explanation for Group 1 and Group 2 in the text) are shown by dashed line (Group 1) and solid line (Group 2).

\section{Calculating empirical Green's functions and dispersion curves}

For evaluation of EGFs we applied pre-processing procedure that includes pre-filtering in the frequency band of $0.1-1 \mathrm{~Hz}$; deconvolution of instrument responses; and removing record parts with earthquakes, quarry blasts and explosions, and a high signal-to-noise ratio. After that, we calculated crosscorrelation functions between all pairs of the DAFNE stations. Whitening was not applied. Figure 10a, $\mathrm{b}$ and $\mathrm{c}$ show Green's functions calculated between station DF01 and all other stations of the DAFNE array.

In Fig. 10 one can see that EGFs are asymmetric for pairs of stations with small interstation distances and symmetric for station pairs with large interstation distances. The asymmetry can be explained by non-uniformed azimuthal distribution of noise sources, different distances between stations and selected frequency band.

For extraction of dispersion curves, we applied narrow band pass filters with widths of $0.125 \mathrm{~Hz}$ to surface wave parts of all EGFs. We measured group velocities, but for the selected frequency band they can be approximately taken as phase velocities for dispersion curve evaluation.

Some of the station pairs of the DAFNE array have interstation distances less than the wavelength for some frequencies. That is why the corresponding calculated velocities had large error bars. These velocities were excluded from further processing. Some dispersion curves contained fundamental and the first higher mode of Rayleigh wave (Fig. 11). In our study we did not use the first higher mode and used fundamental mode only.

Figure 12 shows all dispersion curves selected for the analysis. As can be seen, the scatter of dispersion curves is large and distribution of them is generally bimodal. Dispersion curves for intermediate interval with velocities between 
(a)

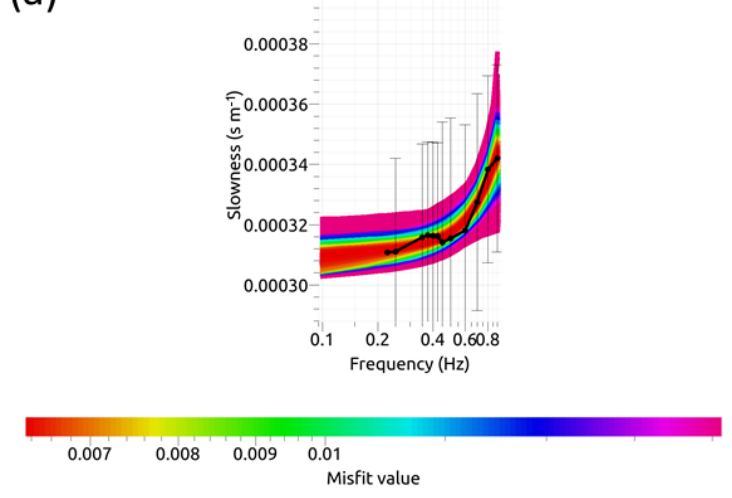

(b)

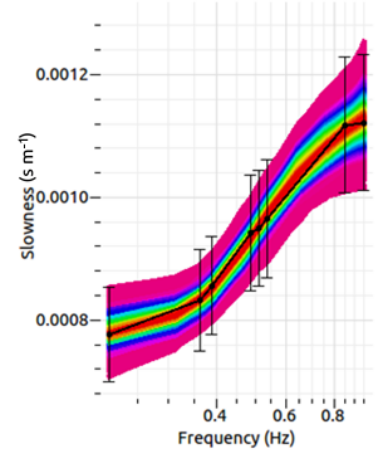

$0.007 \quad 0.0080 .0090 .01$

Misfit value

Figure 13. Results of inversion of averaged dispersion curves for station pairs of Group 1 (a) and Group 2 (b). The plots demonstrate the fit of model dispersion curves to the observed dispersion curve marked by the solid black line with the corresponding error bar. An ensemble of all models that equally fits the data and prior information is shown by colour plots, in which the colour scale indicates the value of misfit function.

(a)

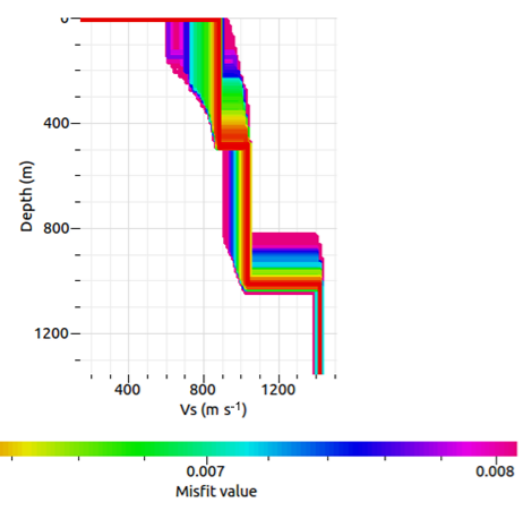

(b)

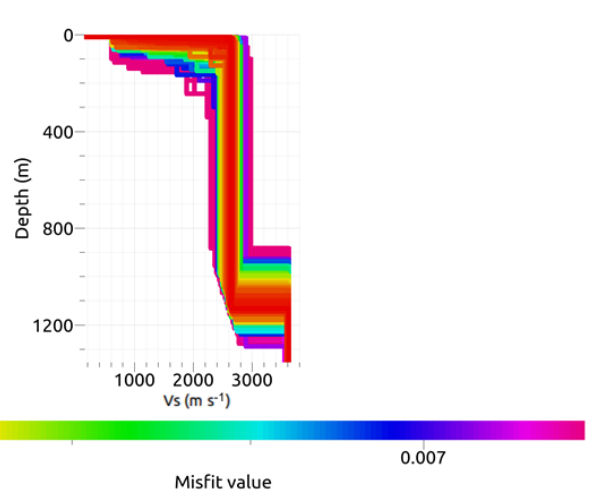

Figure 14. Results of inversion of averaged dispersion curves for station pairs of Group 1 (a) and Group 2 (b). The plots demonstrate the ensemble of all velocity models that equally fit the data and prior information. The colour scale indicates the value of the misfit function.

2000 and $3000 \mathrm{~m} \mathrm{~s}^{-1}$ correspond to waves propagating both along and across the fault zone, and the number of dispersion curves for this velocity interval is small. Because of this, inversion results for this group of curves would be not stable. In our study we discuss only results for which it was possible to obtain stable and statistically significant inversion results. We separately calculated averaged dispersion curve for EGFs corresponding to two groups of station pairs. The first group (referred hereafter as Group 1) is composed of the pairs in which stations are installed on different sides of the fault or on top of the fault, and the second group (hereafter Group 2) is composed of the pairs of stations installed on the same side of the fault and of the pairs with one of the stations (or both stations) installed on the fault. Figure 12 shows comparison of two different dispersion curves corresponding to Group 1 and Group 2.

In Fig. 12 one can see that dispersion curve for Group 1 indicates significantly smaller velocities than the dispersion curve for Group 2. This result suggests that seismic velocities inside the fault zone are most probably significantly different from those outside the fault zone. Therefore, we decided to determine this difference using inversion of these two dispersion curves separately.

\section{Inversion of dispersion curves}

For inversion of dispersion curves we used the Geopsy software (www.geopsy.org). The software uses the neighbourhood global optimization algorithm by Sambridge (1999), modified by Wathelet (2008). As solutions of geophysical inverse problems are generally non-unique, the ideal solution in this method is made of the ensemble of all models that equally fit the data and prior information.

Table 3 presents the starting model and constraints on model parameters we used in inversion. Parameters of the uppermost layer of the model ( $V_{\mathrm{p}}, V_{\mathrm{s}}$ and density) were obtained from results of $\mathrm{H} / \mathrm{V}$ analysis presented in our study and parameters for the other layers were constrained using 
Table 3. Parameters of the starting velocity model for inversion of dispersion curves.

\begin{tabular}{lrrr}
\hline Depth (m) & $\begin{array}{r}V_{\mathrm{p}} \\
\left(\mathrm{m} \mathrm{s}^{-1}\right)\end{array}$ & $\begin{array}{r}V_{\mathrm{s}} \\
\left(\mathrm{m} \mathrm{s}^{-1}\right)\end{array}$ & $\begin{array}{r}\text { Density } \\
\left(\mathrm{kg} \mathrm{m}^{-3}\right)\end{array}$ \\
\hline $5-15$ & 700 & 350 & 1500 \\
$200-700$ & 6150 & 3590 & 2030.27 \\
$800-2300$ & 6350 & 3710 & 2096.27 \\
$15000-20000$ & 6300 & 3650 & 2079.77 \\
\hline
\end{tabular}

the P- and S-wave velocity models from previous study by Janik et al. (2009). These models were obtained for seismic controlled-source profiles closest to our study area.

We applied about 500 iterations for calculation of 1-D velocity models with minimum misfit function value. The results of inversion for two dispersion curves corresponding to Group 1 and Group 2 are presented in Fig. 13a and b and Fig. 14a and b. Figure 13a and b show two ensembles of calculated dispersion curves compared to two observed dispersion curves and Fig. 14a and b show two corresponding ensembles of velocity models. The values of the misfit function for each element of solutions ensemble are denoted by the colour scale in both figures. The error bars for the dispersion curve for pairs of stations outside the fault are larger than those for the dispersion curve for pairs of stations across the fault. This can be explained by variations in seismic velocities in the near-fault zone.

Figure 14a shows that 1-D S-wave velocity model for pairs of stations of Group 1 consists of three layers with low velocities (about $900-400 \mathrm{~m} \mathrm{~s}^{-1}$ ). The pronounced velocity boundary is located at a depth of about $1000 \mathrm{~m}$. For the pairs of stations of Group 2 the 1-D velocity model consists of two layers with generally higher velocities than in the previous case (from 2500 to $3500 \mathrm{~m} \mathrm{~s}^{-1}$ ). As the Green's functions estimated by cross-correlation of recordings of two stations are dependant on the structure between them, this result suggests that an area exists inside the fault zone with seismic velocities significantly lower than those of the bedrock outside the fault zone.

\section{$7 \quad$ Discussion and conclusions}

Two major results obtained in our study can be formulated as follows:

1. Suasselkä postglacial fault zone is still seismically active, as shown by distribution of hypocentres of local earthquakes from the fault area detected by the DAFNE array.

2. Analysis and inversion of averaged dispersion curves obtained from EGFs for two groups of seismic stations pairs (e.g. the pairs in which stations are located on opposite sides of the fault and the pairs in which stations are located outside the fault) revealed significant (about $1000 \mathrm{~m} \mathrm{~s}^{-1}$ ) difference between seismic velocities inside the fault zone and outside the fault zone.

Unfortunately, we not able to analyse trapped waves in our study, unlike in the study by Allam et al. (2014). The main reason for this was that the events considered in our study were weak compared to those used for investigation of trapped waves in modern active fault areas. That is why the signal from them was seen clearly at the nearest stations only. At remote stations the signal-to-noise ratio was poor and correlation of phases corresponding to trapped waves was not possible.

As shown in Figs. 2 and 3, regional seismic networks did not register any earthquakes originating from the SPGF area, neither prior to DAFNE experiment nor during the time period considered in Sect. 3. In spite of that, we revealed a number of natural events using the data of the dense DAFNE array installed in the vicinity of the fault. This suggests that the magnitudes of these events are smaller than the magnitude detection threshold for the present configuration of permanent seismic stations. Analysis of the FENCAT catalogue shows that no events originating from northern Finland with local magnitude $\left(M_{\mathrm{L}}\right)$ less than 0.7 were detected during the DAFNE data acquisition period. Hence, our study suggests that local magnitudes of events detected in our study are less than 0.7 and the value of 0.5 can be assumed as a conservative estimate. The more precise magnitude estimate was difficult to do in our study, as the events were seen on band-passfiltered recording only and such a filtering generally distorts the amplitudes of seismic signal.

Concerning the low velocities inside the fault area, these velocities cannot be explained by sediments because results of the H/V analysis presented in Sect. 4.3 suggest that the thickness of sediments is smaller than $5 \mathrm{~m}$ in our study area. Therefore, the most plausible explanation is that the lowvelocity area is a fractured zone inside the fault that can correspond to the fault damage zone (FDZ). The velocities outside the fault zone are typical S-wave velocities in the felsic rocks of the uppermost crystalline crust documented in a petrophysical study of Finnish bedrock by Kern et al. (1993). The rough estimate of the width of this zone corresponds to a smaller wavelength in the considered frequency band of $0.1-1 \mathrm{~Hz}$ and is about $1.5 \mathrm{~km}$. This is in a good agreement with the recent results of Valoroso et al. (2013), who estimated the width of the seismically active L'Aquila fault zone using analysis of high-precision earthquake locations spanning 1 year. They showed that the width of the fault zone varies along strike from $0.3 \mathrm{~km}$, where the fault exhibits the simplest geometry and experienced peaks in the slip distribution, up to $1.5 \mathrm{~km}$ at the fault tips, with an increase in the geometrical complexity.

The velocity boundary at a depth of about $1200 \mathrm{~m}$ is seen in both velocity models obtained from average dispersion curves for Group 1 and Group 2. The origin of this 
boundary is not clear, but it cannot correspond to the lower boundary of the FDZ, as seismic velocities obtained for the Group 1 are lower than those for the Group 2 down to the depth of $1300 \mathrm{~m}$. However, we can speculate that the lower boundary of the fault damage zone may correspond to the sub-horizontal area of high reflectivity revealed by Abdi et al. (2015). The authors also demonstrated the complex structure of the fault area down to a depth of 2-3 km, with two sets of segmented and discontinuous dipping reflectors. Slip on small-scale fractures corresponding to these reflectors may be the explanation of small magnitude of events detected by our study.

In summary, our study revealed that the SPGF is still seismically active and that a non-healed mechanically weak fault damage zone (FDZ) exists in the fault area. Most probably, the FDZ was formed after the last major earthquake that occurred after the last glaciation. This suggests that the SPGF has the potential for future reactivation. Our study also confirms that analysis of EGFs estimated by cross-correlation can be an efficient tool in investigating the inner structure of seismogenic faults.

Data availability. The data of the DAFNE project are free for scientific purposes. However, at the date of this publication, they have yet not published in public data repositories. It is foreseen that the data will be published and distributed via EPOS (European Plate Observing System) data services.

Team list. The DAFNE/FINLAND Working Group consists of the following individuals: Ilmo Kukkonen (University of Helsinki, Department of Physics, Helsinki, Finland), Pekka Heikkinen (University of Helsinki, Institute of Seismology, Helsinki, Finland), Kari Komminaho (University of Helsinki, Institute of Seismology, Helsinki, Finland), Elena Kozlovskaya (Oulu Mining School, University of Oulu/ Geological Survey of Finland, Oulu, Finland), Riitta Hurskainen (Sodankylä Geophysical Observatory, University of Oulu, Oulu, Finland), Tero Raita (Sodankylä Geophysical Observatory, University of Oulu, Oulu, Finland), Hanna Silvennoinen (Sodankylä Geophysical Observatory, University of Oulu, Oulu, Finland).

Competing interests. The authors declare that they have no conflict of interest.

Acknowledgements. The present paper was a part of research projects DAFNE (Drilling into Active Faults in Northern Europe).

The study was partly funded by Posiva Oy and Geological Survey of Finland. The authors are grateful to the technical unit of the SGO for service of the DAFNE station during experiment. We give our particular thanks to Inna Usoskina, who performed tremendous work with manual analysis of the FINLAND/DAFNE data and event relocation for this study. The digital aeromagnetic map of Finland was provided by the Geological Survey of Finland.
Geopsy software (www.geopsy.org) was used for ambient noise analysis and inversion of dispersion curves. We very much appreciate the detailed and constructive comments of Alireza Malehmir, Gregor Hillers and the anonymous reviewer, which help to improve an earlier version of the manuscript.

This work was supported in part by the Federal Agency of Scientific Organizations, project no. AAAA-A16-116052710111-2.

Edited by: T. Nissen-Meyer

Reviewed by: G. Hillers and one anonymous referee

\section{References}

Ahmadi, O., Juhlin, C., Ask, M., and Lund, B.: Revealing the deeper structure of the end-glacial Pärvie fault system in northern Sweden by seismic reflection profiling, Solid Earth, 6, 621-632, doi:10.5194/se-6-621-2015, 2015.

Allam, A. A., Ben-Zion, Y., and Peng, Z.: Seismic Imaging of a Bimaterial Interface Along the Hayward Fault, CA, with Fault Zone Head Waves and Direct P Arrivals, Pure Appl. Geophys., 171, 2993, doi:10.1007/s00024-014-0784-0, 2014.

Brandes, C., Winsemann, J., Roskosch, J., Meinsen, J., Tanner, D.C., Frechen, M., Steffen, H., and Wu, P.: Activity of the Osning thrust during the late Weichselian: Ice-sheet and lithosphere interactions, Quaternary Sci. Rev., 38, 49-62, doi:10.1016/j.quascirev.2012.01.021, 2012.

Bratt, S. R. and Bache, T. C.: Locating Events with a Sparse Network of Regional Arrays, B. Seismol. Soc. Am., 78, 780-798, 1988.

Campillo, M.: Phase and correlation of "random" seismic fields and the reconstruction of the Green function, Pure Appl. Geophys., 163, 475-502, doi:10.1007/s00024-005-0032-8, 2006.

Chester, F. M. and Logan, J. M.: Composite planar fabric of gouge from the Punchbowl Fault, California, J. Struct. Geol., 9, 621634, 1986.

Cochran, E., Li, Y-G., Shearer, P. M., Barbot, S., and Vidale, J. E.: Seismic and geodetic evidence for extensive, long-lived fault damage zones, Geology, 37, 315-318, doi:10.1130/G25306A.1, 2009.

Crone, A. J., De Martini, P. M., Machette, M. N., Okmura, K., and Prescott, J. R.: Paleoseismicity of two historically quiescent faults in Australia: Implications for fault behaviour in stable continental regions, B. Seismol. Soc. Am., 93, 1913-1934, 2003.

Davis, G. H. and Reynolds, S. J.: Structural Geology of Rocks and Regions, Wiley, New York, 1996.

Douze, E. J. and Laster, S. J.: Statistics of semblance, Geophysics, 44, 1999-2003, doi:10.1190/1.1440953, 1979.

Gebrande, H., Kern, H., and Rummel, F.: Elasticity and Inelasticity. In: Landolt-Börnstein Tables, Group V, edited by: Angenheister, G., Springer-Verlag, Berlin, 1-233, 1982.

Glitterman, Y. and van Eck, T.: Spectra of quarry blasts and microearthquakes recorded at local distances in Israel, B. Seismol. Soc. Am., 83, 1799-1812, 1993.

Glitterman, Y. and Shapira, A.: Spectral classification methods in monitoring small local events by the Israel seismic network, J. Seismol., 2, 237-256, 1998. 
Hillers, G., Campillo, M., Ben-Zion, Y., and Roux, P.: Seismic fault zone trapped noise, J. Geophys. Res.-Sol. Ea., 119, 5786-5799, doi:10.1002/2014JB011217, 2014.

Janik, T., Kozlovskaya, E., Heikkinen, P., Yliniemi, J., and Silvennoinen, H.: Evidence for preservation of crustal root beneath the Proterozoic Lapland-Kola orogen (northern Fennoscandian shield) derived from $\mathrm{P}$ - and S- wave velocity models of POLAR and HUKKA wide-angle reflection and refraction profiles and FIRE4 reflection transect, J. Geophys. Res., 114, B06308, doi:10.1029/2008JB005689, 2009.

Juhlin, C. and Lund, B.: Reflection seismic studies over the endglacial Burträsk fault, Skellefteå, Sweden, Solid Earth, 2, 9-16, doi:10.5194/se-2-9-2011, 2011.

Juhlin, C., Dehghannejad, M., Lund, B., Malehmir, A., andPratt, G.: Reflection seismic imaging of the end-glacial Pärvie Fault system, northern Sweden, J. Appl. Geophys., 70, 307-316, 2010.

Kern, H., Walther C., Flüh, E. R., and Marker, M.: Seismic properties of rocks exposed in the POLAR profile region - constraints on the interpretation of the refraction data, Precambrian Res., 64, 169-187, 1993.

Kaikkonen, T.: Kalliopinnan topografian määrittäminen geofysikaalisilla tutkimuksilla hangaskankaan pohjavesialueella Oulussa, MSc Thesis, University of Oulu, 2007 (in Finnish).

Kim, Y.-S., Peacock, D. C. P., and Sanderson, D. J.: Fault damage zones, J. Struct. Geol., 26, 503-517, 2004.

Kujansuu, R.: Recent faults in Lapland, Geologi, 16, 30-36, 1964 (in Finnish)

Kuivamäki, A., Vuorela, P., and Paananen, M.: Indications of postglacial and recent bedrock movements in Finland and Russian Karelia, Geological Survey of Finland, Report YST-99, Espoo, 92 pp., 1998.

Kukkonen, I., Olesen, O., and Ask, M. V. S.: PFDP Working Group. Postglacial faults in Fennoscandia: targets for scientific drilling, Journal of geological society of Sweeden, 132, 71-81, 2010.

Malehmir, A., Andersson, M., Mehta, S., Brodic, B., Munier, R., Place, J., Maries, G., Smith, C., Kamm, J., Bastani, M., Mikko, H., and Lund, B.: Post-glacial reactivation of the Bollnäs fault, central Sweden - a multidisciplinary geophysical investigation, Solid Earth, 7, 509-527, doi:10.5194/se-7-509-2016, 2016.

McKenna, J., Stein, S., and Stein, C. A.: Is the New Madrid seismic zone hotter and weaker than its surroundings? in: Continental Intraplate Earthquakes: Science, Hazard and Policy Issues, edited by: Stein, S. and Mazotti, S., Geological Society of America Special Paper 425, 167-175, doi:10.1130/2007.2425(12), 2007.

Mikko, H., Smith, C. A, Lund, B., Ask, M., and Munier, R.: LiDAR-derived inventory of 25 post-glacial fault scarps in Sweden, J. Geol. Soc. Sweden, 137, 334-338, doi:10.1080/11035897.2015.1036360, 2015.

Nakamura, Y: A method for dynamic characteristics estimation of subsurface using microtremor on the ground surface. Railway Technical Research Institute, Quarterly Reports, 30, 25-33, 1989.

Neiddell, N. and Turhan Taner, M.: Semblance and other coherency measures for multichannel data, Geophysics, 36, 482-497, 1971.

Olesen, O., Blikra, L. H., Braathen, A., Dehls, J. F., Olsen, L., Rise, L., Roberts, D., Riis, F., Faleide, J. I., and Anda, E.: Neotectonic deformation in Norway and its implications: a review, Norw. J. Geol., 84, 3-34, 2004.
Paananen, M.: Geophysical studies of the Venejärvi, Ruostejärvi, Suasselkä and Pasmajärvi postglacial faults in northern Finland, Geological Survey of Finland, Nuclear Waste Disposal Research Report YST-59, 45, 1987.

Palmu, J. P., Ojala, A. E., Ruskeeniemi, T., Sutinen, R., and Mattila, J.: LiDAR DEM detection and classification of postglacial faults and seismically-induced landforms in Finland: a paleoseismic database, Journal of Geological Society of Sweden, 137.4, 344-352, 2015.

Poli, P., Pedersen, H. A., Campillo, M., and the POLENET/LAPNET Working Group: Emergence of body waves from cross-correlation of short period seismic noise, Geophys. J. Int. 188, 549-588, 2012a.

Poli, P., Pedersen, H., Campillo, M., and LAPNET Working Group: Body-wave imaging of Earth's mantle discontinuities from ambient seismic noise, Science, 338, 1063-1065, doi:10.1126/science.1228194, 2012b.

Poli, P., Campillo, M., Pedersen, H., and the POLENET/LAPNET Working Group: Noise directivity and group velocity tomography in a region with small velocity contrasts: the northern Baltic shield application to the northern Baltic Shield, Geophys. J. Int., 192, 413-424, doi:10.1093/gji/ggs034, 2013.

Rost, S. and Thomas, C.: Array seismology: methods and applications, Rev. Geophys., 40, 2-1-2-27, doi:10.1029/2000RG000100, 2002.

Sambridge, M.: Geophysical inversion with a neighbourhood algorithm-I. Searching a parameter space, Geophys. J. Int., 138, 479-494, 1999.

Schweitzer, J., Fyen, J., Mykkeltveit, S., Gibbons, S. J., Pirli, M., Kühn, D., and Kværna, T.: Seismic Arrays, In New Manual of Seismological Observatory Practice(NMSOP-2). GFZ German Research Centre for Geosciences (Deutsches GeoForschungsZentrum GFZ), ISBN 3-9808780-0-7.9., 1-80, 2012.

SESAME H/V User Guidelines: Guidelines for the implementation of the $\mathrm{H} / \mathrm{V}$ spectral ratio technique on ambient vibrations - measurements, processing and interpretations, SESAME European research project, deliverable D23.12, 2005.

Shapiro, N. M. and Campillo, M.: Emergence of broadband Rayleigh waves from correlations of the ambient seismic noise, Geophys. Res. Lett, 31, L07614, doi:10.1029/2004GL019491, 2004.

Shapiro, N. M, Campillo, M., Stehly, L., and Ritzwoller, M. H.: High-Resolution Surface-Wave tomography from ambient seismic noise, Science, 307, 1615-1618, 2005.

Shipton, Z. K. and Cowie, P. A.: A conceptual model for the origin of fault damage zone structures in high-porosity sandstone, J. Struct. Geol., 25, 333-344, 2003.

Sutinen, R., Hyvönen, E., and Kukkonen, I.: LiDAR detection of paleolandslides in the vicinity of the Suasselkä postglacial fault, Finnish Lapland, Int. J. Appl. Earth Obs., 27, 91-99, 2014.

Stein, S.: Approaches to continental intraplate earthquake issues, in: Continental Intraplate Earthquakes: Science, Hazard and Policy Issues, edited by: Stein, S. and Mazotti, S., Geological Society of America Special Paper, 425, 1-16, doi:10.1130/2007.2425(01), 2007.

Valoroso, L., Chiaraluce, L., Piccinini, D., Di Stefano, R., Schaff, D., and Waldhauser, F.: Radiography of a normal fault system by 64,000 high-precision earthquake locations: The 2009 L'Aquila 
(central Italy) case study, J. Geophys. Res.-Sol. Ea., 118, 11561176, doi:10.1002/jgrb.50130, 2013.

Vidale, J. E. and Li, Y.-G.: Damage to the shallow Landers fault from the nearby Hector Mine earthquake, Nature, 421, 524-526, doi:10.1038/nature01354, 2003.

Wathelet, M.: An improved neighborhood algorithm: Parameter conditions and dynamic scaling, Geophys. Res. Lett., 35, L09301, doi:10.1029/2008GL033256, 2008.
Wu, P., Johnston, P., and Lambeck, K.: Postglacial rebound and fault instability in Fennoscandia, Geophys. J. Int., 139, 657-670, 1999.

Zigone, D., Ben-Zion, Y., Campillo, M., and Roux, P.: Seismic Tomography of the Southern California Plate Boundary Region from Noise-Based Rayleigh and Love Waves, Pure Appl. Geophys., 172, 1007-1032, doi:10.1007/s00024-014-0872-1, 2015. 